\title{
Real-Time Implementation of BESS to Smooth the Output Power Fluctuation of Variable Speed Wind Turbine Generator
}

\author{
Adnan Sattar* Non-member, Ahmed Al Durra* Non-member \\ Cedric Caruana* Non-member, S. M. Muyeen ${ }^{* a)} \quad$ Non-member \\ Junji Tamura** Member
}

(Manuscript received Jan. 18, 2013, revised Sep. 25, 2013)

\begin{abstract}
In this paper, a grid connected variable speed wind turbine (VSWT) PMSG integrated with the NaS-type battery energy storage system (BESS) is modeled in the real-time digital simulator (RTDS) to analyze the performance in a real system. This study is also a part of the future power hardware-in-loop (PHIL) test; therefore, individual components are modeled from the practical standpoint. The wind turbine, power grid, and control system are modeled in the largetime-step main network; however, the wind generator (PMSG), frequency converter (FC), and BESS integrated with STATCOM are modeled in the RTDS VSC small-time-step network to take into consideration the higher-switchingfrequency phenomena. The interface transformer is used to connect the different-time-step subnetworks. The option of integrating the anemometer is kept open for a future PHIL test. The simulation results are compared with those obtained from the laboratory standard power system software PSCAD/EMTDC to validate the model developed in the RTDS/RSCAD.
\end{abstract}

Keywords: PMSG, ESS, NaS, STATCOM, RTDS, PSCAD

\section{Introduction}

Renewable energy sources often produce power and voltage fluctuations with natural conditions (wind speed, solar irradiance, etc). However, electric utility grid systems cannot readily accept connection of new generation plant without strict conditions placed on voltage regulation due to real power fluctuation and reactive power generation or absorption, and on voltage waveform distortion resulting from harmonic currents injected by nonlinear elements of the plant ${ }^{(1)}$. Fluctuating wind speed also causes the system frequency to deviate from the $50 \mathrm{~Hz}$ standard, as many protection relays have the frequency margin of $1 \%$, which causes the malfunction of the power system protection equipment ${ }^{(2)}$. As a result, it has become the major concern for the Transmission System Operators (TSO) or the utility companies to resolve the wind power smoothing issue ${ }^{(3)(4)}$. Energy Storage System (ESS) is needed to smooth the intermittent output power fluctuations of the wind farm. A lot of choices for the ESS are present nowadays in the market, e.g., Pumped Hydro Energy Storage (PHES), Compressed Air Energy Storage (CAES), Flywheel, Super Capacitors Energy Storage (SES), Superconducting Magnetic Energy Storage (SMES), Hydrogen Energy Storage System (HESS), Batteries Energy Storage System (BESS), etc, which are used to overcome the fluctuated wind farm output power ${ }^{(5)}$.

\footnotetext{
a) Correspondence to: S. M. Muyeen. E-mail: smmuyeen@pi.ac.ae

* The Petroleum Institute

Abu Dhabi, UAE P.O Box 2533

${ }^{* *}$ Kitami Institute of Technology

Kitami, Hokkaido 090-0015, Japan
}

The choice of the ESS in the electric system network depends upon the desired application. To meet the electric power quality problems, energy storage with fast response rate and ability to charge/discharge many times is needed ${ }^{(6)}$. For the time scale of seconds-to-minutes, a suitable energy storage system is needed to have a good ramp rates, and, as discussed earlier, flywheel, super capacitors, and batteries might be a good option ${ }^{(7)}$. Besides that, the chosen energy storage system should be able to provide rated power for longer periods. However, for the longer time scales, the charging/discharging rate becomes less important and the choice of the ESS depends upon the amount of stored energy and the power capacity ${ }^{(8)}$. Currently, the Pumped Hydro Storage System (PHSS) is the most common storage technology for longer time scales applications ${ }^{(9)}$.

Different types of batteries are presented as the substantial choice for the ESSs which are Sodium Sulfur (NaS), LithiumIon (Li-ion), Nickel-metal, Nickel-cadmium, and Lead-acid batteries. Among different types of batteries, Lead-acid is the most popular and oldest technology. It has low capital investment and has the vast experience of usage. However, lead-acid batteries require frequent maintenance, they have short life (often 3-5 years), risk of explosions and acid leaking, and thus they are not environment friendly. They are majorly used as backup sources nowadays ${ }^{(10)}$. Nickel-cadmium type battery appears as an alternative for the lead-acid battery. They have longer life time, less temperature dependent, and high charge rates. They have a disadvantage of crystallization; it decreases the capacity of the battery when the battery is idled. Nickel-metal type hybrid battery has higher energy density as compared to the lead-acid and nickel-cadmium, 
but they need a special charging control ${ }^{(11)}$.

Sodium-Sulfur $(\mathrm{NaS})$ type battery system has a modular structure. It is the most recent technology among other technologies of the batteries. They are manufactured by the NGK insulators Ltd. Japan and are widely used nowadays in renewable applications as the energy storage system. $\mathrm{NaS}$ uses the molten metal and operates at temperature above $250^{\circ} \mathrm{C}$. They have very high power densities and works good for storing bulk amount of power. They have longer life time i.e. 15 years and they are relatively inexpensive ${ }^{(12)(13)}$.

The behavior of the Renewable energy sources (RES) are based on the weather conditions, e.g., wind, solar irradiance, temperature; therefore it is not feasible to study and investigate the behavior of the RES through direct implementation as the setup is very expensive. These RES are extensively equipped with modern power electronic inverter/converter. The exact switching behavior of those power electronic converters cannot be mimicked when offline simulation tools are used in simulating the system and therefore, prototype, and control algorithm validation in real-time before integrating with RES is also not possible. Therefore, the necessity of experimental tests and measurements without the direct usage of the RES including power electronic interfacing has increased nowadays. Real-time simulators are a complementary power system analyzing tool to conventional power system offline simulation programs e.g. PSCAD/EMTDC, Simulink, etc., for power system studies. Real-time simulators are able to simulate very complex and large power system models in real-time. The simulation time-step of a real-time simulator is very small as tens of microseconds at the CPU, and tens of nanoseconds at the field-programmable gate array (FPGA). Therefore, real-time simulators can be used to study phenomena over a broad time frame, from less than $1 \mathrm{~ms}$ to minutes and hours ${ }^{(14)-(17)}$ and can be used for power hardware-in-loop (PHIL) and control hardware-inloop (CHIL) testing.

Some work has been carried out in real-time simulators to analyze the different applications of RES. In Refs. (18)(20), LVRT characteristics of the VSWT-PMSG are analyzed using the RTDS simulator by the controller hardwarein-loop (CHIL) method. Real-time analysis of the enhancement of the transient characteristics of fixed speed wind farms are analyzed by using a reduced scale STATCOM Prototype by using the OPAL-RT simulator ${ }^{(21)}$. Literatures on power hardware-in-loop (PHIL) simulations, solar energy, hybrid vehicles, fuel cell in real-time simulators are found in Refs. (22)-(25).

The contribution of this research is to investigate and study the behavior of the variable speed wind farms integrated with the battery energy storage system in real-time using RTDS based on the actual weather conditions, which is wind speed in this case. This work is also a part of the future power hardware-in-loop (PHIL) test and therefore, the component models, especially power electronic converter modules are developed considering the realistic scenario and the developed control scheme can be used for prototype testing purpose. Frequency converter used with PMSG and STATCOM with BESS part are modeled using small-time-step, so that the real power electronic switching behavior is mimicked which is not possible when offline simulation tools are used. A comparative analysis is also carried out with the offline simulation tool, PSCAD to identify the difference from where the necessity of using RTDS can be understood.

\section{Modeled System}

The model system used in this study is shown in Fig. 1, in which individual wind generators in a wind farm is connected to the grid through the machine-side inverter (MSI), DC link and grid-side converter (GSC). The Permanent magnet synchronous generator (PMSG) is used as wind generator, and battery energy storage system (BESS) is adopted as the ESS. BESS consist of a DC-DC buck-boost converter, DC-AC converter, and a DC link capacitor, connected to the point of common coupling (PCC). Anemometer is considered to measure the wind speed signals from the real world. The wind speed is stored in the file and used in the wind turbine model of the RSCAD by using the scheduler to generate the torque for the wind generator. Hence this is the most accurate way of analyzing the behavior of the wind energy conversion system at different weather conditions.

\section{Real-Time Digital Simulator (RTDS)}

Real-time digital simulator (RTDS) is a real-time implementation of the electromagnetic type simulation of the power system models. RTDS is based upon the combination of advanced computer hardware and widespread software. RTDS has custom powerful computation platform, used to solve the non-linear differential equations. In this way, the

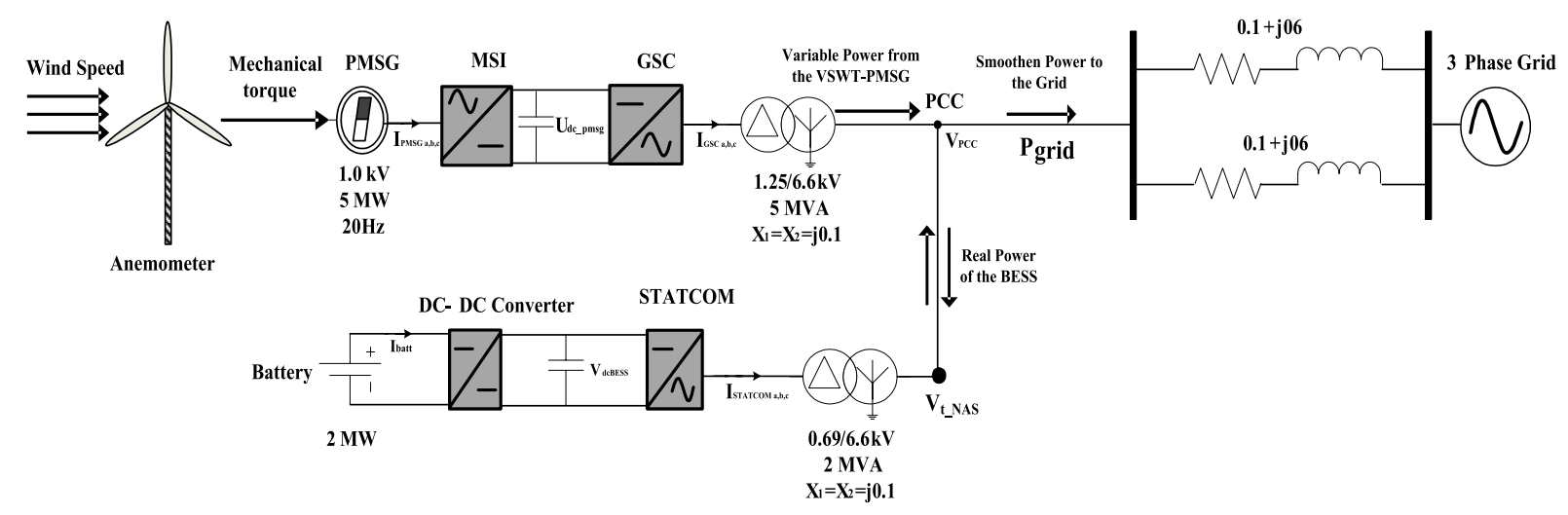

Fig. 1. Model system 
system size to be run is not limited by one processor or one computer, therefore, power system network consisting of hundreds of buses can be simulated in real-time. RTDS hardware is based upon the advanced parallel processing techniques which are based upon the Digital signal processors (DSP) in order to have reduced computation burden for the real-time operation. The RTDS hardware interacts with the RSCAD software during run time and thus performs all the computations in real-time. In order to maintain the real-time operation, different racks can be utilized. Each rack consists of processing cards (triple processor card (3PC), operating at $80 \mathrm{MHz}$, RISC Processor Card (RPC) operating at $600 \mathrm{MHz}$, Gigabyte processing card (GPC) operating at $1 \mathrm{MHz}$ and communication card. The most recent and powerful card among all other cards are PB5, it consist of two POWERPC RISC processor operating at $1.7 \mathrm{GHz}$. Digital and analogue $\mathrm{I} / \mathrm{O}$ ports are also available with the processing cards. All these cards are connected with each other using the common backplane and hence facilitate the exchange of data between the individual processors and between different racks. The RTDS has a graphical user interface, named RSCAD software, which allows the user's interface with the hardware. It also allows the user to construct the simulation circuit, run, operate and record the results. RSCAD consists of multiple modules like Draft, RunTime, T-LINE, Multiplot, Cable and CBuilder (component builder). The power system modeling can be done in two different appsroaches. Firstly, the dual-time-step approach and secondly the largetime-step approach. In dual-time-step approach, some parts of the power system and control system which requires high precision (high switching frequency) is modeled in the smalltime-step $(<4 \mu \mathrm{s})$ and some are modeled in the large-timestep $(50 \mu \mathrm{s})$ network. Both-time-step network simulated systems are interfaced by the interfaced transformer. While in the large-time-step approach, all the power system components and the control system are modeled in the large-timestep network. The RTDS Simulator (shown in Fig. 2) in the Renewable Energy LAB of The Petroleum Institute contains 4 racks, 3 are mounted in the cubicle frame and one portable

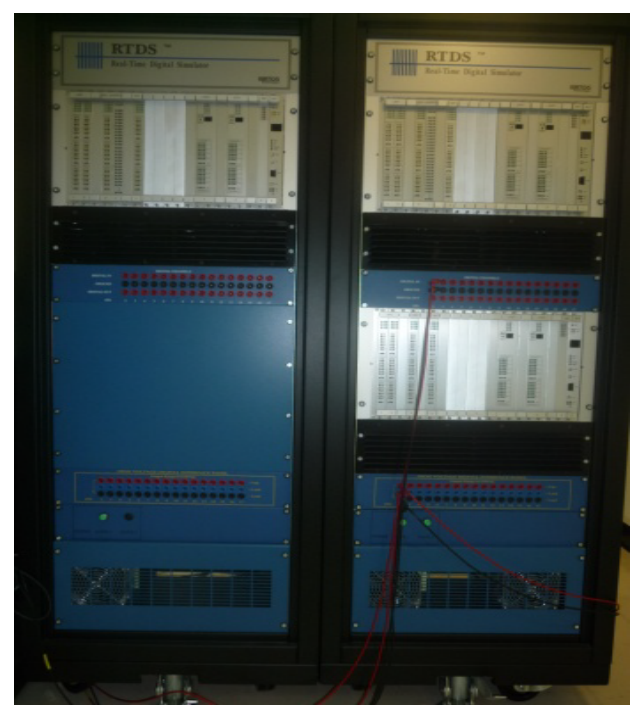

Fig. 2. RTDS Installed at Renewable Energy Lab of The Petroleum Institute, Abu Dhabi, UAE rack. Each rack has 4 3PC cards including 1 DOPTO card, 2 GPC card, 1 IRC and 1 WIF card.

\section{Real-time Modeling of the Battery Energy Storage System}

The battery is represented by a simple model consisting of a constant internal resistance in series with a variable internal electromotive force. The battery operation is limited from fully charged to $70 \%$ depth of discharge in order to preserve the battery lifetime. A $2 \mathrm{MW} 2.86 \mathrm{MWh}$ battery with an open circuit voltage of $0.472 \mathrm{kV}$ (at $35 \%$ discharge) is used.

The battery internal electromotive force is assumed to vary linearly with the discharge energy level $E$. As shown in Fig. 3, when the battery is discharged at the rated power for one hour,

$$
2[M W] * 3600[\mathrm{sec}]=7200[\mathrm{MJ}]
$$

The stored energy drops by $70 \%$ while the internal electromotive force only drops by $10 \%$ to $0.9 \mathrm{~V}_{\mathrm{O}} . \mathrm{V}_{\mathrm{O}}$ is the internal electromotive force when the battery is fully charged. The internal electromotive force $\mathrm{V}_{\text {int }}$ can then be expressed as in (2). Given the open circuit voltage at $35 \%$ discharge, $V_{O}$ is equal to $0.497 \mathrm{kV}$. The battery is considered to be initially charged to $65 \%$ of its total capacity.

$$
V_{\text {int }}=\left(1-\frac{E}{72000}\right) V_{0} \ldots \ldots \ldots \ldots \ldots \ldots \ldots
$$

The internal resistance of the battery $\mathrm{R}_{\mathrm{NaS}}$ is taken to cause a voltage drop equal to $5 \%$ of the internal electromotive force when the battery is delivering rated power at $35 \%$ discharge level. The battery terminal voltage $\mathrm{V}_{\mathrm{NAS}}$ at such condition is then equal to $0.449 \mathrm{kV}$ as obtained from (3).

$$
\begin{aligned}
\left.V_{N a S}\right|_{35 \%} & =0.95 V_{o}-I_{N a S} R_{N a S}=(1-0.05) \cdot 0.95 V_{0} \\
& =0.9025 V_{o} \ldots \ldots \ldots \ldots \ldots \ldots \ldots \ldots \ldots \ldots \ldots \ldots
\end{aligned}
$$

Given the battery rated power of $2 \mathrm{MW}$, the current $\mathrm{I}_{\mathrm{NAS}}$ can be determined from (4). $R_{\mathrm{NaS}}$ is then at $0.0053 \Omega$, as obtained from the voltage drop expression in (3),

$$
P_{\text {nas }}=V_{\mathrm{NaS}} * I_{\mathrm{NaS}}
$$

The battery internal electromotive force at 35\% discharge is known, at $0.472 \mathrm{kV}$. The internal force $\mathrm{V}_{\text {int }}$ variation is assumed to vary linearly with the discharge energy level, as

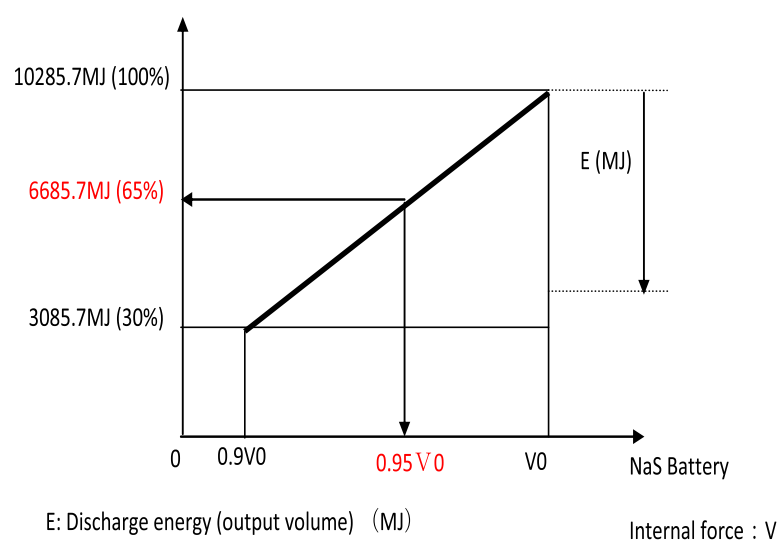

Fig. 3. Characteristic of the NaS type battery 
shown in Fig. 3. Hence the voltage $\mathrm{V}_{\mathrm{O}}$ can be easily determined.

The BESS is connected to the buck boost DC-DC converter and thus an appropriate control strategy is adopted for the smoothing operation through the charging/discharging of the BESS.

The battery current can be easily obtained since the output power $\mathrm{P}_{\mathrm{NAS}}$ is known and the terminal voltage $\mathrm{V}_{\mathrm{NAS}}$ can be easily determined.

$\mathrm{V}_{\mathrm{NaS}}=0.449 \mathrm{kV}, \mathrm{P}_{\mathrm{NaS}}=2 \mathrm{MW}$, by using the Eq. (4), the battery current can be calculated, thus, $\mathrm{I}_{\mathrm{NAS}}=4.4577 \mathrm{kA}$.

\section{Battery Integrated with STATCOM}

STATCOM is identified as the fast-responding VAR compensating device, and thus it can be used for the improvement of the power quality and stability problems of the wind farm. Previous studies of the STATCOM are limited only up to the reactive power compensation ${ }^{(26)}$, but with the recent advancement of the BESS, it is possible to control the real power as well using BESS integrated with STATCOM system on the DC side. Thus it has become possible to control the real and reactive power independently. Studies in Ref. (27) show that the BESS integrated with STATCOM could solve the power fluctuation problems besides that it also improves the stability of the wind farms during the short circuit disturbances by supplying the adequate reactive power support to the system. Besides that, it also has other possible applications, e.g. voltage control, frequency regulation, and power oscillation damping ${ }^{(28)}$.

5.1 BESS Control Strategy The main objective of this control scheme is to intermittent the output power fluctuations of the VSWT generator. Therefore, a simple control strategy is taken into consideration for the control of the buck-boost DC-DC converter. The control block diagram of the buck boost converter is shown in Fig. 4. It operates by controlling the switches of the buck boost converter in ON and OFF operations. When the power flowing to the grid, $\mathrm{P}_{\text {grid }}$, is less than the desired set reference power, $\mathrm{P}_{\text {ref }}$, the battery discharges and thus works in boost converter operation mode, and when the power flowing to the grid is more than the $\mathrm{P}_{\text {ref }}$, then the battery charges and works in the buck mode operation. The error signal between the $\mathrm{P}_{\text {grid }}$ and $\mathrm{P}_{\text {ref }}$ is set through the PI controller and then compared with the triangular carrier wave generator in order to generate the switching pulses for the buck boost converter switches. The frequency of the triangular wave is chosen to be $600 \mathrm{~Hz}$. Besides that, the state of charge (SOC) of battery is also considered. As it is not desired to completely discharge or overcharge the battery, the SOC of the battery should be kept within the proper limits i.e. between 30\%-70\%.

5.2 STATCOM Control Strategy Figure 5 shows the control block diagram of the 2 level VSC based STATCOM. The main objective of the control of STATCOM is to provide the rapid reactive power support and keep the terminal voltage constant at its rated value. By combining the BESS with STATCOM, it offers the control of the active power, as discussed earlier. The well-known cascaded vector control scheme is developed. The three phase electrical and dq quantities are related with each other by the reference frame transformation. The transformation angle is calculated

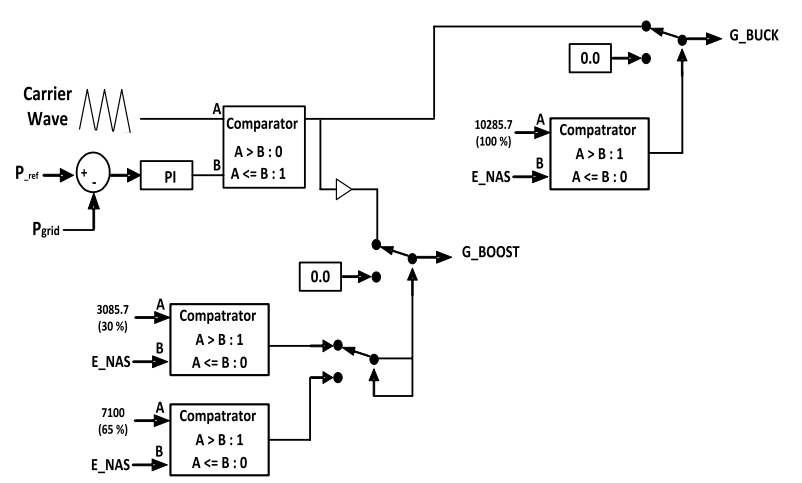

Fig. 4. Control block diagram of the BESS

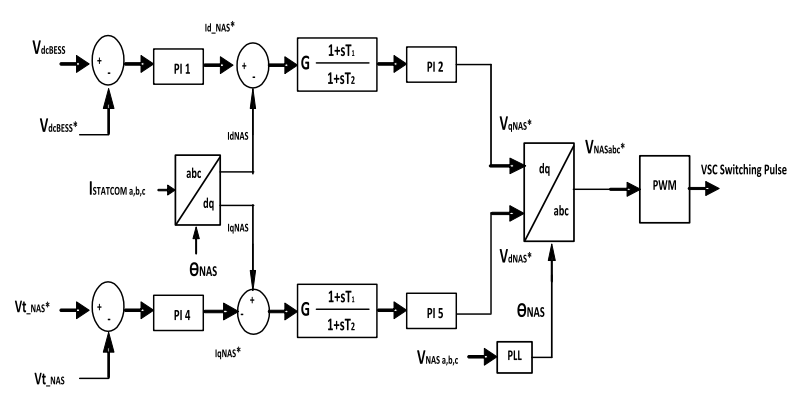

Fig. 5. Control block diagram of VSC based STATCOM

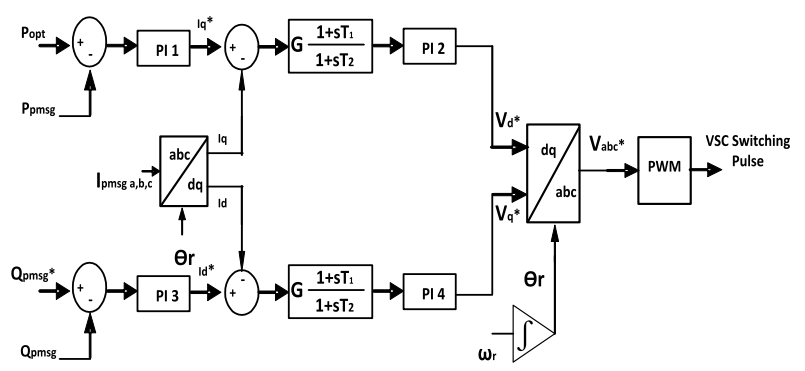

Fig. 6. Block diagram of the Machine Side Inverter

by the phase locked loop (PLL) by measuring the three phase voltage signals at the $\mathrm{PCC}^{(29)}$ where the terminal of the $\mathrm{NaS}$ battery is also connected.

5.3 PMSG and Frequency Converter Control In this study, direct driven PMSG is connected to the grid through fully controlled frequency converters (FC). The FC is composed of 2-level voltage source converter, called machine-side inverter, (MSI) and grid side-converter (GSC), which are connected back-to-back.

The MSI is connected with the stator of the PMSG which efficiently decouples the PMSG to the grid, thus allowing the rotor of the wind turbine and generator to rotate freely depending on the wind speed conditions. Figure 6 shows the control block of the MSI. Cascaded vector control scheme is used to control the real and reactive power of the PMSG generator. Park transformation is used for the reference frame transformation. The transformation angle $\Theta_{\mathrm{r}}$ is calculated by integrating the rotor speed of the generator. The real power reference is set in such a way to extract the maximum power from the wind energy. The reference of the reactive power is set to zero for unity power factor operation.

Figure 7 shows the control block diagram of the GSC. The first objective of the control system is to keep the DC link voltage constant and thus ensuring that active power 


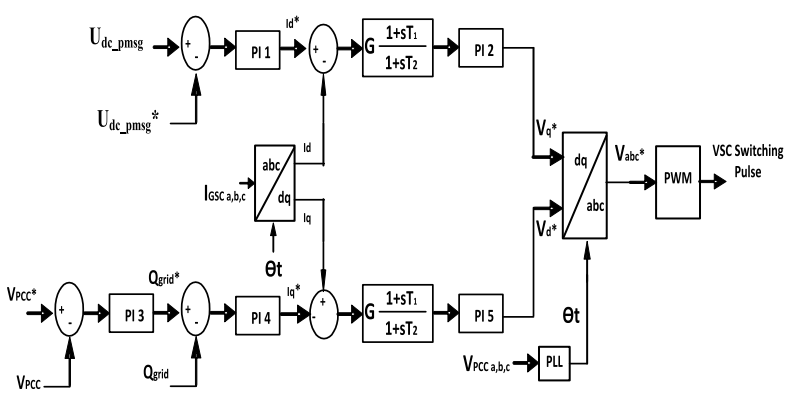

Fig. 7. Block diagram of the Grid Side Converter

generated by the PMSG is fed into the grid. The second is to control the terminal voltage through the reactive power fed to or absorbed from the grid. The GSC is controlled in the synchronous reference frame. The transformation angle is calculated from the three phase voltages at the high voltage side of the transformer connected at the grid side by using the PLL.

\section{Switching Scheme in RTDS}

A Pulse width modulation (PWM) scheme is used to generate the switching pulses for the frequency converters and STATCOM. RTDS large-time-step is used to generate the carrier and modulation signals. These signals are then transferred to the VSC small-time-step network to generate the triangular wave by using the triangular wave generator module. VSC small-time-step firing pulse generator module is used to generate the high resolution firing pulses in the small-timestep environment by comparing the carrier wave and reference voltage signals. The GTO valves can get the firing pulse by selecting the option CC_WORD of the GTO Bridge ${ }^{(30)-(32)}$.

\section{Real-time Simulation Setup}

In this study, the VSWT-PMSG along with the back to back converters and the BESS integrated with the STATCOM are modeled in the small-time-step of the RSCAD in order to take into consideration the higher switching frequency phenomena. The control models are developed in the large-time-step of the RSCAD. Two VSC small-time-step blocks are used; one consists of the model of the VSWT-PMSG including the MSI, DC Link and GSC, and the other consists of the BESS integrated with the STATCOM. The two VSC small-timestep blocks are solved on the different processors of the GPC cards, where the different time-steps models are interfaced each other through the interface transformers. Wind turbine, transmission line and power grid are modeled in the RTDS large-time-step and are solved on the 3PC card. The control blocks are modeled in the large-time-step and are solved on the GPC card; switching signals for the switches are generated in the small-time-step. The processor assignments used to solve the power network in RTDS are shown in Fig. 8.

\section{Simulation Results}

In this paper, dynamic characteristic is analyzed when the NaS type battery energy storage system (BESS) integrated with the STATCOM is connected at wind farm terminal to smooth the output power fluctuations. Real wind speed data is measured, stored in data file, and used in RTDS environment using scheduler which will finally be replaced

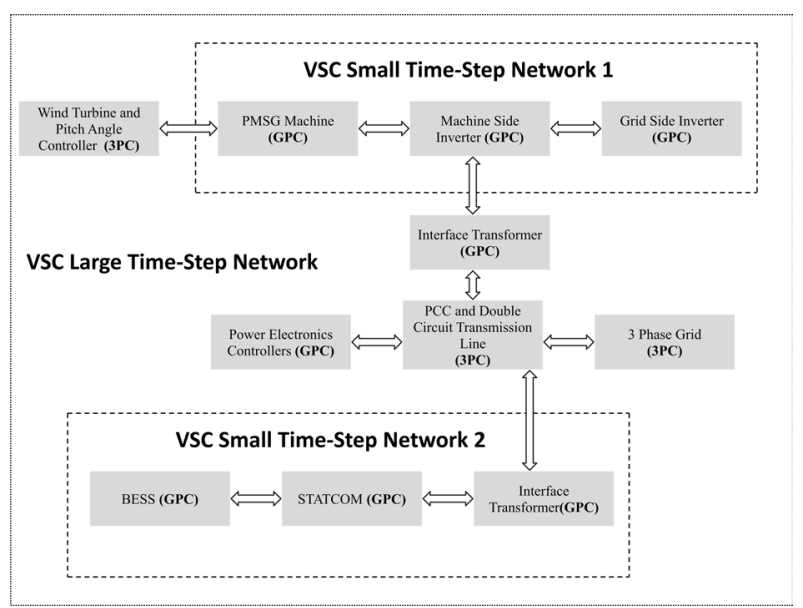

Fig. 8. Block diagram of the modules and processor assignments

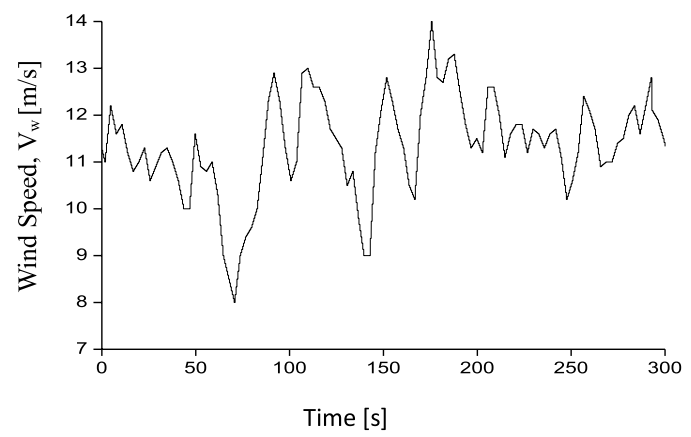

Fig. 9. Real-time wind speed data

with advanced anemometer equipped with remote data logger. Simulation results for the 300 seconds of wind speed data are shown. Switching frequency for the frequency converters, DC-DC converter and STATCOM are chosen to be $1050 \mathrm{~Hz}, 600 \mathrm{~Hz}$ and $1000 \mathrm{~Hz}$ respectively. RTDS smalltime-step for the VSC network 1 and 2 is $2.4 \mu$ s and $2.14 \mu \mathrm{s}$ respectively and large-time-step is chosen to be $50 \mu \mathrm{s}$. RTDS simulation results are also compared with those obtained by the PSCAD/EMTDC where time-step is chosen to be $20 \mu \mathrm{s}$. The PI controller parameters are obtained by the trial and error method to obtain the finest performance.

8.1 RSCAD/RTDS Simulation Results Wind speed data shown in Fig. 9 is used in the wind turbine to generate the torque for the PMSG for 300 seconds. Figure 10 shows the RTDS responses of the VSWT-PMSG output and smooth power to the utility grid along with the reference power signal. Figure 11 shows the response of the DC link bus voltage of the BESS, and response of the terminal voltage at the point of common coupling (PCC) is shown in Fig. 12. The energy level of BESS that is dissipated and absorbed during the operation and real power of the battery are shown in Figs. 13 and 14 respectively. Though the DC link voltage is fluctuating due to the wind farm output fluctuations and switching operation of buck-boost converter, it is kept within $\pm 5 \%$ of the rated value. The RMS voltage at PCC is kept almost constant at the rated value.

8.2 PSCAD/EMTDC Simulation Results Figure 15 till 19 shows the PSCAD/EMTDC simulation results of the smooth power supplied to the grid, DC link bus voltage of 


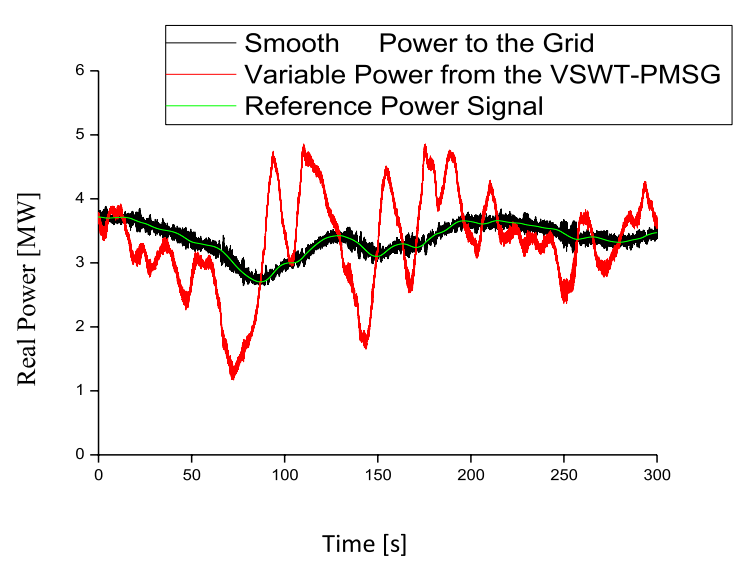

Fig. 10. RTDS responses of wind farm output, supplied power to the grid and reference power signal

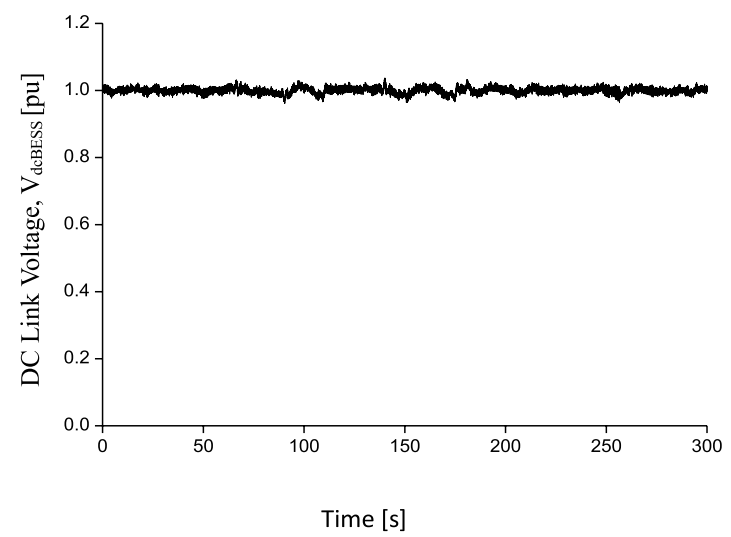

Fig. 11. RTDS response of DC Link bus voltage of the BESS



Fig. 12. RTDS response of RMS voltage at PCC

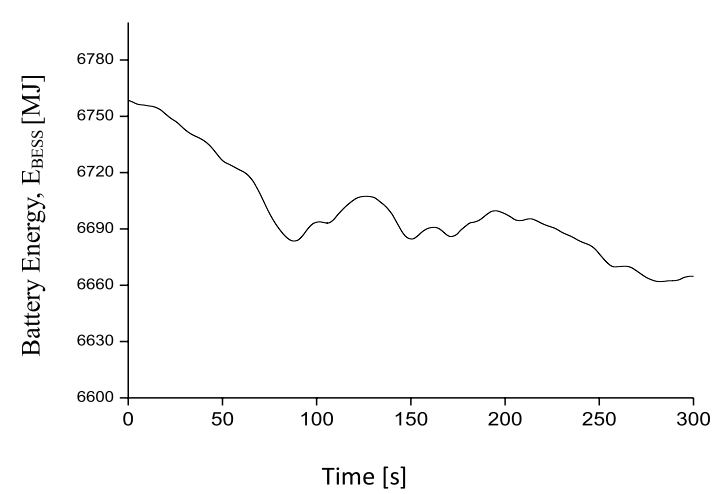

Fig. 13. RTDS response of energy level of the BESS



Fig. 14. RTDS response of real power supply/absorption of the BESS

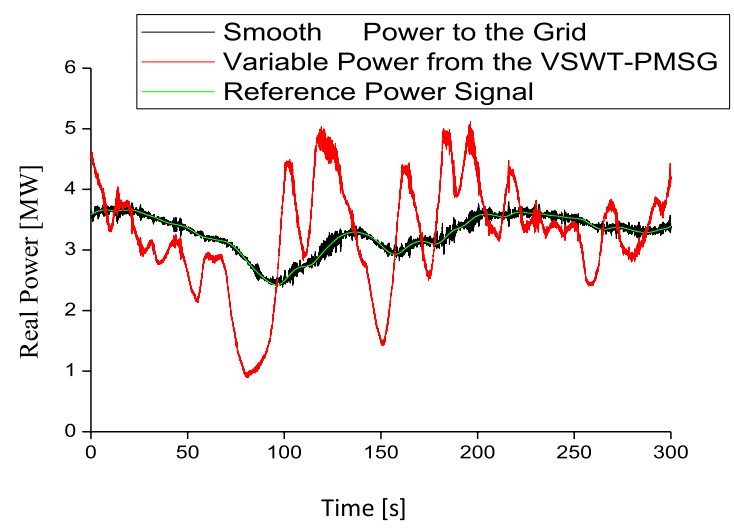

Fig. 15. PSCAD/EMTDC responses of wind farm output, supplied power to the grid and reference power signal

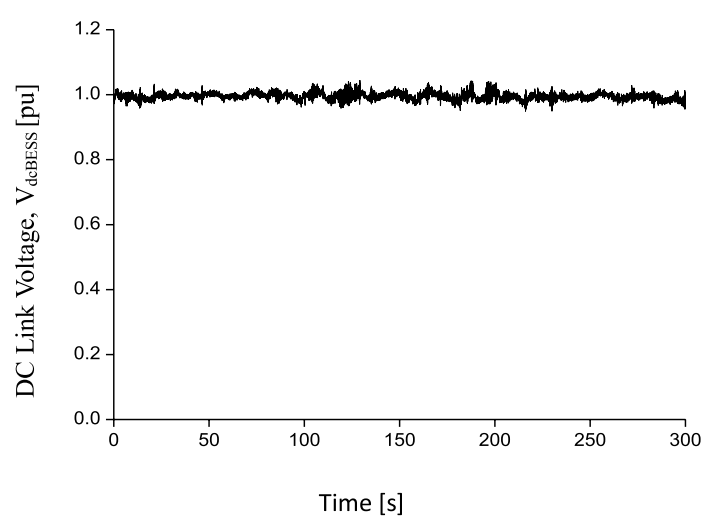

Fig. 16. PSCAD/EMTDC response of DC Link bus voltage of the BESS

BESS, RMS voltage at PCC, energy of the BESS and real power supply/absorption by the BESS. The results shows good agreement with the RSCAD results, but the variations in the RMS voltage, DC link bus voltage and power supplied to the grid are different from the RTDS results. This is because, as the RSCAD uses small-time-step for the simulation, the switching phenomena in the power electronic switches can be analyzed accurately and the results are close to the realtime operation.

Comparative analyses have been carried out where dynamic characteristics are analyzed for $300 \mathrm{~s}$ of real wind speed data using both PSCAD/EMTDC and RTDS/RSCAD. RTDS required almost the same time of about $310 \mathrm{~s}$ to 




Fig. 17. PSCAD/EMTDC responses of RMS voltage at PCC

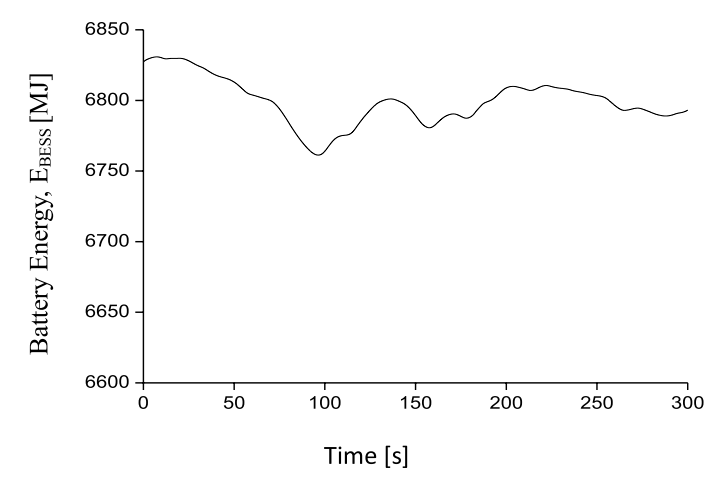

Fig. 18. PSCAD/EMTDC response of energy level of the BESS

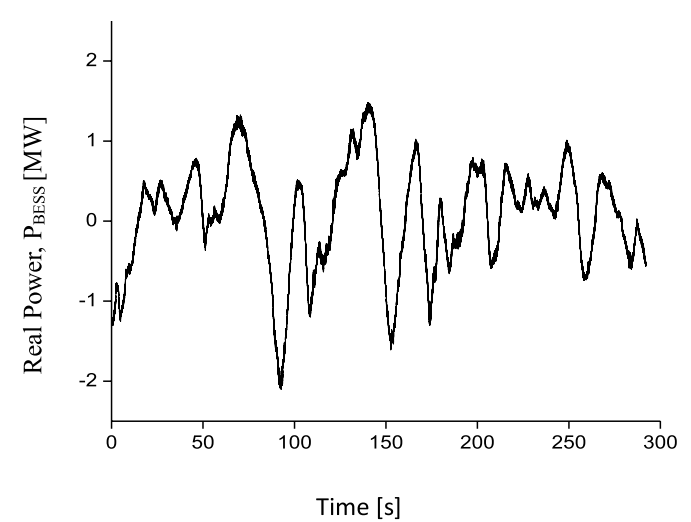

Fig. 19. PSCAD/EMTDC response of real power supplied/absorb of the BESS

download and plot the result as the simulation time. However, PSCAD/EMTDC took almost 320 minutes to finish the simulation of $300 \mathrm{~s}$. Therefore, it is quite difficult to perform dynamic analysis including power smoothing, optimum capacity determination for BESS, etc., for longer time in the range of hour or day using offline simulation tools. Hence, RTDS is an effective means to solve these problems.

\section{Conclusion}

In this study, detailed modeling of the grid connected VSWT-PMSG and the NaS type BESS integrated with STATCOM is carried out in the VSC small-time-step of the RTDS. Simulation results show the effectiveness of the control algorithms developed for controlling the BESS. RTDS simulation results are compared with the laboratory standard offline simulation tool i.e. PSCAD/EMTDC. VSC small-time-step approach is the most precise method for studying the power system dynamics and power converters operating at higher switching frequencies. For the dynamic characteristics analysis, RTDS is proven as an effective tool due to its high computation capabilities, while the offline simulation tools are accurate but they need very long simulation time, which is not suitable for the dynamic analysis in the range of hours or day.

\section{References}

( 1 ) E.OnNetz, Grid Code, High- and Extra-High Voltage (2006) available at www.eon-netz.com/

( 2 ) C. Luo and B.T. Ooi: "Frequency deviation of thermal power plants due to wind farms", IEEE Trans. Energy Convers., Vol.21, No.3, pp.708-716 (2006)

( 3 ) European Network of Transmission System Operators, $2^{\text {nd }}(2010)$

(4) System operator market service provider, Electricity Authority - New Zealand, $11^{\text {th }}(2011)$

( 5 ) F.V. Hulle: Large Scale Integration of Wind Energy in the European Power Supply Analysis, Issue and Recommendations. EWEA, Tech. Rep. (2005)

( 6 ) K. Divya and J. Ostergaard: "Battery energy storage technology for power systems”, Electr. Power Syst. Res., Vol.79, No.4, pp.511-520 (2009)

( 7 ) H. Ibrahim, A. Ilinca, and J. Perron: "Energy storage systemscharacteristics and comparisons", Renewable and Sustainable Energy Reviews, Vol.12, pp.1221-1250 (2007)

( 8 ) J.P. Barton and D.G. Infield: "Energy storage and its use with intermittent renewable energy", IEEE Trans. Energy Convers., Vol.19, p.441 (2004)

( 9 ) C. Bueno and J.A. Carta: "Wind powered pumped hydro storage systems, a means of increasing the penetration of renewable energy in the Canary Islands", Renewable and Sustainable Energy Reviews, 10, pp.312-340 (2006)

(10) C.J. Rydh: "Environmental assessment of vanadium redox and lead-acid batteries for stationary energy storage", J. Power Sources, 80, pp.21-29 (1999)

(11) Battery Power, Products and Technology: "World's Largest Battery Energy Storage System Completes Third Year of Operation”, Vol.11, No.1 (2007)

(12) M. Beaudin, H. Zareipour, A. Schellenberglabe, and W. Rosehart: "Energy storage for mitigating the variability of renewable electricity sources: An updated review", Energy for Sustainable Development, 14, pp.302-314 (2010)

(13) B. Polgári and B. Hartmann: "Energy Storage Technology for Hungary NaS Battery for Wind Farms", IEEE $3^{\text {rd }}$ International Youth Conf., pp.1-8 (2011)

(14) L.-F. Pak, M.O. Faruque, X. Nie, and V. Dinavahi: "A versatile cluster-based real-time digital simulator for power engineering research", IEEE Trans. Power Syst., Vol.21, No.2, pp.455-465 (2006)

(15) V. Dinavahi, M.R. Iravani, and R. Bonert: "Design of a real-time digital simulator for a D-STATCOM system", IEEE Trans. Ind. Electron., Vol.51, No.5, pp.1001-1008 (2004)

(16) C. Dufour , L.-H. Hoang, J.C. Soumagne, and A. El Hakimi: "Real-time simulation of power transmission lines using Marti model with optimal fitting on dual-DSP card", IEEE Trans. Power Del., Vol.11, No.1, pp.412-419 (1996)

(17) Y. Li, D.M. Vilathgamuwa, and P.C. Loh: "Design, analysis, and real-time testing of a controller for multibusmicrogrid system", IEEE Trans. Power Electron., Vol.19, No.5, pp.1195-1204 (2004)

(18) M. Park, C. Hwang, B.M. Song, and K.Y. Lee: "Voltage Transient Analysis of a PMSG Wind Power System using Controller-Hardware-in-the Loops", IEEE 2011 PES Conf. of Innovation Smart Grid Technologies (2011)

(19) H. Li, M. Steurer, K. Shi, S. Woodruff, and D. Zhang: "Development of a unified design, test, and research platform for wind energy systems based on hardware-in-the-loop real-time simulation", IEEE Trans. Ind. Electron., Vol.53, No.4, pp.1144-1151 (2006)

(20) B.M. Song, C. Hwang, and M. Park: "Analysis of Voltage Faults in the GridConnected Inverter of a Wind Power Generation System using Real-Time Digital Simulator", IEEE 8th International conference on Power Electronics, Korea (2011)

(21) H. Gaztanaga, I. Etxeberria-Otadui, D. Ocnasu, and S. Bacha: "Real-Time Analysis of the Transient Response Improvement of Fixed-Speed Wind Farms by Using a Reduced-Scale STATCOM Prototype", IEEE Trans. on Power Systems, Vol.22, No.2, pp.658-666 (2007)

(22) C. Dufour and J. Belanger: "Real-time PC-based simulator of electric systems and drives", Proc. Int. Conf. Parallel Comput. Elect. Eng., Vol.1, pp.105-113 (2004)

(23) M. Steurer, F. Bogdan, W. Ren, M. Sloderbeck, and S. Woodruff: "Controller and Power Hardware-In-Loop Methods for Accelerating Renewable Energy 
Integration", in Power Engineering Society General Meeting, 2007. IEEE, pp.1-4 (2007)

(24) I.J. van Vliet, et al.: "Real-Time Simulation to Study the impact of Renewable Energy in Power Systems", 2005 Future Power System International Conference, pp.6-12 (2005)

(25) M.J. Tavernini, B.A. Niemoeller, and P.T. Krein: "Real-time low-level simulation of hybrid vehicle systems for hardware-in-the-loop applications", Proc. IEEE Veh. Power Propul. Conf., pp.890-895 (2009)

(26) M. Kamibayashi and K. Tanaka: "Recent Sodium Sulfur Battery Applications", Proc. IEEE PES Transmission and Distribution Conference and Exposition, USA, 2001, Vol.2, pp.1169-1173 (2001)

(27) S. Teleke, M.E. Baran, A. Huang, S. Bhattacharya, and L. Anderson: "Control strategies for battery energy storage for wind farm dispatching", IEEE Trans. Energy Convers., Vol.24, p.725 (2009)

(28) M.E. Baran, S. Teleke, L. Anderson, S. Bhattacharya, A. Huang, and S. Atcitty: "STATCOM with Energy Storage for Smoothing Intermittent Wind Farm Power", IEEE/PES (2008)

(29) A. Arulampalam, M. Barnes, N. Jenkins, and J.B. Ekanayake: "Power quality and stability improvement of a wind farm using STATCOM supported with hybrid battery energy storage", Proc. Inst. Electr. Eng. Gen., Transmiss. Distrib., Vol.153, p.701 (2006)

(30) A. Sattar, A. Al-Durra, and S.M. Muyeen: "Real-time Implementation of STATCOM to Analyze Transient and Dynamic Characteristics of Wind Farm", 37th International Conference on Industrial Electronics, IEEE IECON, Melbourne, Australia (2011)

(31) A. Sattar, A. Al-Durra, and S.M. Muyeen: "Dynamic Characteristics Analysis of Wind Farm Integrated with STATCOM Using RTDS”, 11th International Conference IEEE EPQU 2011, Paper No.182, Lisbon, Portugal (2011)

(32) Real-time Digital Simulator Power System and Control User Manual, RTDS Technologies (2009)

Adnan Sattar (Non-member) received his B.Sc. degree in Electrical

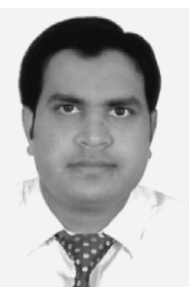
and Electronics Engineering from the Islamic University of Technology (IUT), Dhaka in 2008. He joined the Petroleum Institute in 2010 as a graduate student and finished his M.Sc. degree in Electrical Engineering in 2012. During his master research, he works on the Real-time implementation and control validation of the Wind energy conversion system by using real-time digital simulator (RTDS). His research interests are Wind Energy Conversion Systems, Battery Energy Storage Systems, FACTS, Power hardware-in-loop, controller hardware-in-loop simulations, and RTDS. He is the Student member of IEEE. Presently he is working as the Electrical Engineering in Al Hosn Gas, UAE.

Ahmed Al-Durra (Non-member) received the B.S., M.S., and Ph.D.

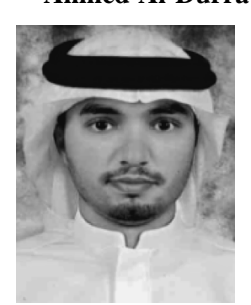
in Electrical and Computer Engineering from the Ohio State University in 2005 , 2007, and 2010, respectively. For his M.Sc. degree, he investigated the application of several nonlinear control techniques on automotive traction PEM fuel cell systems. He conducted his $\mathrm{PhD}$ research at the Center for Automotive Research in the Ohio State University. His $\mathrm{PhD}$ work was on the applications of modern estimation and control theories to automotive propulsion systems." At the present, he is working as Assistant Professor in Electrical Engineering Department at the Petroleum Institute, Abu Dhabi. His research interests are application of estimation and control theory in power system stability and control, energy storage system (ESS), and renewable energy. Dr. Ahmed is a member of IEEE, and ASME.
Cedric Caruana (Non-member) received the Ph.D. degree in Elec-

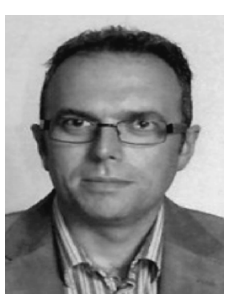
trical Engineering from the University of Nottingham, Nottingham, UK in 2004. He was with Carlo Gavazzi (Malta) Ltd and ST Microelectronics (Malta) Ltd working as a process engineer and senior test engineer respectively. Following the award of his $\mathrm{Ph} . \mathrm{D}$., he joined the Faculty of Engineering, University of Malta, where he is currently a Senior Lecturer. From 2011 to 2012 he was a Visiting Assistant Professor at the Petroleum Institute, Abu Dhabi, UAE. His main research interests are the control of electrical drives, industrial energy efficiency, alternative energy conversion and network integration. He is a senior member of the IEEE and a member of the IET.

S. M. Muyeen (Non-member) received his B.Sc. Eng. degree from

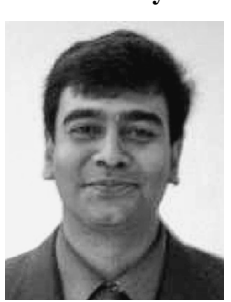
Rajshahi University of Engineering and Technology (RUET), Bangladesh formerly known as Rajshahi Institute of Technology, in 2000 and M.Sc. Eng. and Dr. Eng. degrees from Kitami Institute of Technology, Japan, in 2005 and 2008, respectively, all in Electrical and Electronic Engineering. His Ph.D. research work focused on wind farm stabilization from the viewpoint of LVRT and frequency fluctuation. After completing his Ph.D. program he worked as a Postdoctoral Research Fellow under the versatile banner of Japan Society for the Promotion of Science (JSPS) from 2008-2010 at the Kitami Institute of Technology, Japan. At the present, he is working as Assistant Professor in Electrical Engineering Department at the Petroleum Institute, Abu Dhabi. His research interests are power system stability and control, electrical machine, FACTS, energy storage system (ESS), Renewable Energy, and HVDC system. He has published over 100 international papers. He has published four books as an author or editor. Dr. Muyeen is the senior member of IEEE.

Junji Tamura (Member) received his B.Sc. Eng. degree from Muro-

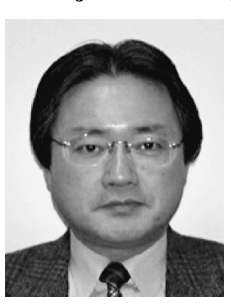
ran Institute of Technology, Japan, in 1979 and M.Sc. Eng. and Dr. Eng. degrees from Hokkaido University, Japan, in 1981 and 1984 respectively, all in electrical engineering. He became a lecturer in 1984, an Associate Professor in 1986, and a Professor in 1996 at the Kitami Institute of Technology, Japan. Currently he is a Vice President of the Kitami Institute of Technology. Dr. Tamura is a Senior Member of the IEEE Power Engineering Society. 